OPEN ACCESS

Edited by:

Md Anwarul Azim Majumder, The University of the West Indies,

Barbados

Reviewed by:

Shamshad Khan,

University of Texas at San Antonio,

United States

Ravindra Kumar Vemula,

English and Foreign Languages

University, India

*Correspondence:

Sanghamitra Pati

drsanghamitra12@gmail.com

tORCID:

Sanghamitra Pati

orcid.org/0000-0002-7717-5592

Rajeshwari Sinha

orcid.org/0000-0001-9369-1477

Pranab Mahapatra

orcid.org/0000-0002-3736-4268

Specialty section:

This article was submitted to

Health Communication,

a section of the journal

Frontiers in Communication

Received: 31 January 2021

Accepted: 10 June 2021

Published: 30 June 2021

Citation:

Pati S, Sinha $R$ and Mahapatra $P$ (2021) Health Communication and Inter-professional Care in Context of

Multimorbidity Management: Assessment of Health Professional

Curricular Focus in India.

Front. Commun. 6:661930.

doi: 10.3389/fcomm.2021.661930

\section{Health Communication and} Inter-professional Care in Context of Multimorbidity Management: Assessment of Health Professional Curricular Focus in India

\author{
Sanghamitra Pati ${ }^{1 *}$, Rajeshwari Sinha ${ }^{2}$ and Pranab Mahapatra ${ }^{3}$ \\ ${ }^{1}$ ICMR Regional Medical Research Centre, Department of Health Research, Bhubaneswar, India, ${ }^{2}$ Independent Researcher, New \\ Delhi, India, ${ }^{3}$ Department of Psychiatry, Kalinga Institute of Medical Sciences, KIIT University, Bhubaneswar, India
}

To meet the long term care demands of chronic diseases as well as multimorbidity, healthcare providers from different disciplines need to work collaboratively in practice. This requires healthcare providers to be appropriately trained on delivery of inter-professional care (IPC) and health communication aspects during formative professional years. In this study, we have looked at the prevailing undergraduate and postgraduate healthcare professional curricula to understand the focus on health communication and on IPC for the delivery of multidisciplinary care for multimorbidity management. We observe that while there are exclusive courses on health communication being delivered at different levels, the focus on IPC is still in stages of infancy. The IPC component is just beginning to be woven into the health professional curricula through elements like competency-based curriculum, rotational posting, inter-departmental engagements. At the same time, the need to put curricular attention on multimorbidity is also highlighted here. There remains wider scope for strengthening learning on health communication and IPC among different disciplines within the curricula in the context of multimorbidity. We expect our findings to provide key inputs to academic planners and policy makers towards the introduction of adequate curricular components for addressing multimorbidity along with necessary prescriptions for health communication and IPC in India.

Keywords: multimorbidity, multiple comorbidities, patient-centred care, primary care, inter-professional care, health communicaiton, health promotion, health education

Abbreviations: AETCOM, Attitude, Ethics and Communication; AIIMS, All India Institute of Medical Sciences; BDS, Bachelor of Dental Surgery; BPT, Bachelor of Physiotherapy; BSc, Bachelor of Science; CMC, Christian Medical College; HIV/AIDS, Human Immunodeficiency Virus/Acquired Immune Deficiency Syndrome; HWC, Health and Wellness Centre; IPC, Interprofessional care; JIPMER, Jawaharlal Institute of Postgraduate Medical Education and Research; MBBS, Bachelor of Medicine and Bachelor of Surgery; MD and MS, Doctor of Medicine and Surgery; MPT, Master of Physiotherapy; MSc, Master of Science; MCI, Medical Council of India; MoHFW, Ministry of Health and Family Welfare; NMC, National Medical Commission; NIRTAR, National Institute of Rehabilitation Training and Research; PGIMER, Postgraduate Institute of Medical Education and Research. 


\section{INTRODUCTION}

With improvement in living condition, health care efficacy and better management of infectious diseases, the world is now transitioning to an ageing population. Corresponding with this is the growing magnitude of both chronic diseases as well as multiple chronic diseases, which is gradually taking shape of a daunting public health care challenge. This problem is more acute in low- and middle-income countries (LMICs) experiencing colliding epidemics of long-standing infectious and chronic non-communicable diseases (NCDs) (Bigna and Noubiap, 2019; Kassa and Grace, 2019).

The concurrent prevalence of multiple chronic conditions, known as multimorbidity, is a frequently observed norm in LMICs. Apart from the risk attributable to individual diseases, patients with multimorbidity have lower functional capacity, exhibit inferior physical and mental health related quality of life, incur higher healthcare expenditure, increased levels of polypharmacy, and heightened risk of hospital admissions and mortality rates (Pati et al., 2015a; Pati et al., 2019a). Though initially thought to be confined to elder age, multimorbidity is now found to have pervaded across younger population and all geographic and socio-economic strata in the country. This is undoubtedly an additional concern posed for health systems, professionals and patients alike.

India, the second largest demography is also witnessing an unprecedented rise in chronic diseases over the past 2 decades (Arokiasamy, 2018). Primary care being integral part of India's public health system has to absorb the major brunt since individuals with multimorbidity are mostly seen by primary care physicians although many of the issues are likely to be of similar importance in secondary care (Sinha and Pati, 2017). Our own study has found the prevalence to be around $1 / 3 \mathrm{rd}$ in primary care patient population (Pati et al., 2015b). There is even significant multimorbidity among patients attending secondary and higher levels of health care, as well as specialized settings like psychiatry or antenatal clinics (Pati et al., 2021a; Pati et al., 2021b).

The management of both chronic diseases and multimorbidity requires a holistic care approach, wherein multiple health professionals from different disciplines work together as a team in the healthcare settings. The harmony and effectiveness of such team-based care delivery would depend on synergy and synchrony across multiple healthcare professionals. With the universal health coverage being implemented in India, the organization of primary care as 'health and wellness centers' (HWC) is one of the critical goals (Lahariya, 2018). These HWCs are expected to deliver comprehensive primary care through an expanded range of services and a multidisciplinary team.

This is linked to the appropriate training of healthcare professionals in their respective formative years on interprofessional care (IPC). The role of better health communication within and beyond health professionals through collaboration between different health care disciplines is equally important. Healthcare professionals are to get first familiarized with these newer dimensions from their very stage of professional curating. One of the ways to achieve the above is that the prescriptions in the curriculum are commensurate as well.

It is therefore necessary to have adequate understanding and evidence on the current situation through a mix of approaches encompassing-curriculum review, primary data from key informants and policy analysis prior to co-creating any intervention. We therefore intended to have an inquiry into the status of health communication in general and IPC in particular within the context of multidisciplinary care for multimorbidity in India. Given the exploratory nature of our inquiry, we decided to undertake only curricular assessment to garner a preliminary understanding to start with. Our objective was 1) to map the extant undergraduate and post graduate health professional curricula (medical, nursing, dentistry, and physiotherapy) in India to see if they directly address multimorbidity and IPC for multimorbidity management, and 2) to identify the elements of health communication dwelling on these aspects. We expect the findings of the curricular assessment would provide key inputs to academic planners and policy makers towards the introduction of adequate curricular components for addressing multimorbidity along with necessary prescriptions for IPC in India. Moreover, it would help provide insights towards designing research tools for primary data collection from multiple stakeholders.

\section{METHODOLOGY}

The present study was carried out from January-December 2019 with a two-fold objective. One was to map the extant health professional curricula in India to identify the elements pertaining health communication, followed by analysis of the curricula with focus on IPC towards delivery of multidisciplinary care for multiple chronic conditions.

A systematic strategy based on our previously used approach was followed for extracting the required information (Pati et al., 2017a; Pati et al., 2019b). First, a thorough internet search was carried out to collect information available in the public domain regarding courses offered in health communication, health education and health promotion. The search was carried out using search engines such as Google, Dogpile wherein a set of keywords such as health communication, health education and health promotion, public health education in India, health communication courses offered in India etc. were used for the search. It was restricted to courses offered in India only. The websites of Medical Council of India (MCI) (now known as the National Medical Commission [NMC]), Ministry of Health and Family Welfare (MoHFW), Indira Gandhi National Open University (IGNOU), All India Institute of Medical Sciences (AIIMS), World Health Organization (WHO) were also looked up. Information related to the courses were collected from the websites of respective institutions. Modules on health communication being delivered as part of journalism or mass communication programmes have been excluded.

The second part of the research involved a similar strategy. Amongst undergraduate curricula, we included Bachelor of Medicine and Bachelor of Surgery (MBBS), Bachelor of 
TABLE 1 | Overview of courses related to health communication, promotion and education offered in India ${ }^{a}$.

\begin{tabular}{|c|c|c|c|c|}
\hline Institution/University & Course/Curriculum & Duration & Type of course & Mode \\
\hline $\begin{array}{l}\text { Symbiosis School of Open and Distance Learning, } \\
\text { Maharashtra }\end{array}$ & Diploma programme in health communication & 1 year & Diploma & On-site \\
\hline Banaras Hindu University, Uttar Pradesh & Post graduate diploma in health communication & 1 year & Post graduate diploma & On-site \\
\hline $\begin{array}{l}\text { National Institute of Health and Family Welfare, New } \\
\text { Delhi }\end{array}$ & $\begin{array}{l}\text { Diploma in health communication, diploma in heath } \\
\text { promotion }\end{array}$ & 1 year & Diploma & $\begin{array}{l}\text { Distance } \\
\text { learning }\end{array}$ \\
\hline $\begin{array}{l}\text { Family Welfare Training and Research Centre, Mumbai } \\
\text { (recognized by International Institute of Population } \\
\text { Sciences (IIPS), a deemed University under the Ministry } \\
\text { of Health \& Family Welfare) }\end{array}$ & Diploma in health promotion education & 1 year & Residential diploma & On site \\
\hline Indira Gandhi National Open University & Diploma in nutrition and health education & 1 year & Diploma & $\begin{array}{l}\text { Distance } \\
\text { learning }\end{array}$ \\
\hline $\begin{array}{l}\text { All India Institute of Hygiene and Public Health, Kolkata } \\
\text { (Affiliated to: West Bengal University of Health Science) }\end{array}$ & Diploma in health promotion and education & 1 year & Diploma & On-site \\
\hline $\begin{array}{l}\text { The Gandhigram Institute of Rural Health \& Family } \\
\text { Welfare Trust, Tamil Nadu (affiliated to Dr.MGR Medical } \\
\text { University) }\end{array}$ & P.G. Diploma in health promotion and education course & 1 year & Diploma & On-site \\
\hline Baba Farid University of Health Sciences & $\begin{array}{l}\text { Post graduate diploma in health promotion and } \\
\text { education }\end{array}$ & 1 year & Diploma & On-site \\
\hline Central Health Education Bureau & PG diploma in health education & 2 years & Diploma & On-site \\
\hline SNDT Women's University, Maharashtra & Master of science- nutrition and health communication & 2 years & Master of Science & On-site \\
\hline All India Institute of Medical Sciences & Health education as a module & 5 years & MBBS & On-site \\
\hline SRM Institute of Science and Technology & $\begin{array}{l}\text { Health promotion and behaviour change } \\
\text { communication as a module }\end{array}$ & 2 years & Master of public health & On-site \\
\hline $\begin{array}{l}\text { Indian Institute of Public Health Gandhinagar (Public } \\
\text { Health Foundation of India) }\end{array}$ & Health education and promotion as a module & 2 years & Master of public health & On-site \\
\hline Manipal Academy of Higher Education, Karnataka & Health communication as a module & 2 years & Master of public health & On-site \\
\hline Indian Institute of Healthcare Communication & $\begin{array}{l}\text { Communication skills enhancement program for the } \\
\text { clinicians, nurses and healthcare support staff; clinical } \\
\text { communication skills training for medical/dental } \\
\text { students }\end{array}$ & - & $\begin{array}{l}\text { Healthcare communication } \\
\text { training programs }\end{array}$ & - \\
\hline $\begin{array}{l}\text { Lippincott Gurukul, an eLearning platform, Wolters } \\
\text { Kluwer India }\end{array}$ & Healthcare communication & - & - & Online \\
\hline
\end{tabular}

${ }^{a}$ Table provides few examples; may not be exhaustive.

Science (BSc) in Nursing, Bachelor of Dental Surgery (BDS), and Bachelor of Physiotherapy (BPT). We additionally reviewed post graduate curricula namely Doctor of Medicine and Surgery (MD \& MS), Master of Dental Surgery (MDS), Master of Science (MSc) in Nursing, Master of Physiotherapy (MPT) to garner a better understanding. Since, institution-level curriculum w.r.t. IPC towards delivery of multimorbidity care was not yet incorporated during the time of the research period, we reviewed the curricula/syllabi prescribed by the NMC, Indian Nursing Council, Dental Council of India and Rehabilitation Council of India. The keywords used for the search in this case included terms like MBBS, BSc Nursing, BDS, BPT, MD, MS, MSc Nursing, MDS, MPT, Bachelor of Science in Nursing, Bachelor of Dental Surgery, Bachelor of Physiotherapy, Master of Science in Nursing, Master of Dental Surgery, Master of Physiotherapy, nursing, dentistry, physiotherapy, medicine, medical education, syllabus, comorbidity, multiple morbidity, multiple chronic diseases, multiple chronic conditions, disease cluster, shared care, chronic care model, team based care, long term care, holistic care, integrated care, and patient-centred care. The designated syllabi were carefully examined for class room teaching, practical and patient ward duties or hours and details were noted. In parallel, websites of MoHFW, and few key universities and autonomous institutions offering any or all of the MBBS, BSc Nursing, BDS and BPT courses (e.g., AIIMS Delhi, JIPMER, PGIMER, CMC, and NIRTAR) were browsed to gather necessary information. The curricula were assessed to ascertain whether it has focus on multimorbidity or on IPC and understand if there was any scope of learning other disciplines as part of the patient care teaching or during resident duty. The searches were restricted to full-time courses offered only in India, while shortterm courses offered by various institutions were not considered. The relevant observations captured were further analysed.

\section{RESULTS}

\section{Assessment of Extant Health Professional Curricula With Focus on Health Communication, Promotion and Education}

Table 1 gives an overview of the courses related to health communication/promotion/education which are offered in India. Select institutions are providing these courses in India. We see that of the programmes offered, a number of them are one-year diploma courses imparted as full time or distance learning programmes. In some cases, health communication or education is included as part of a Master of Science (MSc) or 
Master of Public Health or MBBS degree programme, where duration of study is beyond one year. In a similar exercise conducted by us in 2012, we had reported that these aspects are also being taught as modules in Master of Public Health degrees, or in an integrated manner in the community medicine component of undergraduate and postgraduate medical curriculum (Pati et al., 2012). In addition to this, there are also trainings and online courses with focus on health communication.

\section{Assessment of Extant Health Professional Curricula With Focus on IPC Towards Delivery of Multidisciplinary Care for Multiple Chronic Conditions}

A review of the extant undergraduate and postgraduate curricula in India within disciplines of medicine, dentistry, nursing and physiotherapy available in public domain was carried out from the perspective of IPC towards delivery of multidisciplinary care for multiple chronic conditions. Since these elements have not yet been specifically included at the institutional level curricula, our observations from the overarching prescribed curriculum in the fields of medicine, dentistry, nursing and physiotherapy are discussed here.

\section{Undergraduate Curriculum}

The MCI (now known as the National Medical Commission since September 2020), recommends the Competency Based Undergraduate Curriculum for the Indian Medical Graduates (National Medical Commission). The curriculum aims to promote the practice of holistic medicine and prepare the student to be able to work in an inter-professional healthcare team, respecting the diversities of roles, responsibilities and competencies of other professionals. A new and longitudinal programme based on attitude, ethics and communication (AETCOM) competencies that can help train students on competencies such as collaboration, working in interdisciplinary teams has been included within this curriculum. The curriculum also refers to understanding of aetiology, epidemiology, pathogenesis, complications, health risks etc. of specific chronic conditions like cardiovascular diseases, hypertension, obesity, diabetes, blindness, and mental illness etc., but there is limited focus on specific concepts of multimorbidity. There is however focus on developing the graduate's skill to elicit, document and present medical history on comorbidities linked to diabetes, hypertension, and obesity.

The curriculum for BSc Nursing also embraces a competencybased approach (Indian Nursing Council) It is designed to prepare a graduate nurse to deliver patient-centred holistic care, functioning effectively among interdisciplinary and interprofessional teams. It promotes the idea of team based and collaborative learning through inter-professional education by allotting specific study hours to two subjects, namely 1) Educational Technology in Nursing Education and 2) Nursing Management and Leadership. This includes time allotted for both theory and practical classes. Under the Educational Technology in Nursing Education, active learning strategies such as peer sharing, problem based learning are also encouraged. Similar observations were made in case of the MBBS and BSc Nursing curriculum of AIIMS Delhi, which is autonomous institution.

The BDS Course Regulations 2007 (with Amendments) identifies that one of the components of the undergraduate dental course is training on general medicine and general surgery in order to provide the graduate sufficient knowledge on human diseases and its manifestations w.r.t. practice of dentistry (Dental Council of India). It also recognizes the need for the dental graduate to understand the relationship between oral and other systematic diseases. The syllabus of study mentions that training in behavioural sciences should be integrated with all departments of Dentistry, Medicine, Pharmacology, Physiology. and Biochemistry. It touches upon management of dental problems in case of medically compromised patients such as with hypertension or diabetes. The dental internship curriculum provides scope of providing exposure to the student to a functioning healthcare team including multipurpose workers, health educators, and others.

The MOHFW in 2017 released a Model Curriculum Handbook of Physiotherapy with an aim to reduce variations across different courses of physiotherapy study, and to provide a national standard which can be followed (Ministry of Health and Family Welfare, Government of India). Like in cases of other disciplines, the MoHFW also recognizes the development of skill and competency based curriculum for physiotherapy education. It prioritizes team-based provision of healthcare services where healthcare workers work in collaborations within and across settings.

\section{Postgraduate Curriculum}

We also assessed the post graduate syllabi offered in disciplines of medicine, nursing, dentistry and physiotherapy. In the medicine discipline, curricula for 29 subjects under MD, six subjects under MS were analysed (National Medical Commission). Some of the common features that were found to encourage inter-professional engagement under these subjects are discussed below:

- Rotational posting of postgraduate student in various specialties or sub-specialties. The curriculum mentions that students are to be attached to appropriate, related allied departments on a rotation basis for designated amount of time within the post graduate training programme. As part of this attachment, students should take part in all routine activities of the department. In some cases, rotation is encouraged for all departments. Apart from clinical departments, exposure of working in wards, intensive care units, emergency, specialty operation theatres, laboratories, sub-centres and primary healthcare centres, hospitals, clinics etc., is also recommended as part of rotation. Training in clinical departments and support service areas of the hospital is also given consideration in certain cases. There is also provision for post graduate students to attend hospital grand rounds.

- Integrated teaching of undergraduates. Postgraduate students, as per the curricula, are required to participate in the teaching and training programme of undergraduate 
students and interns. They are encouraged to take part in integrated teaching of undergraduates by participation in joint teaching sessions and seminars with different departments, participation in clinical rounds for discussing cases of interest and by small group discussions of case-based problems

- Intra and interdepartmental engagements. The analysed curricula also emphasizes on carrying out intradepartmental and interdepartmental meetings on a regular basis related to discussions on a particular case or interesting medical problems. Interdepartmental learning is also a component of the assessment of the postgraduate curriculum. In some subjects, additional sessions or lectures in allied disciplines are also undertaken.

The MDS course also lays similar stress on rotation and posting in other departments, interdepartmental seminars, lectures taken for undergraduates (Dental Council of India). Across various specialties under the MDS course, there is a component of applied basic sciences which covers teaching on allied topics such as applied anatomy, biochemistry, microbiology, physiology, pathology, pharmacology etc., to enable the candidate to have knowledge of applied basic and systemic medical sciences. This also includes rotation or posting of the postgraduate student in the concerned department for relevant training. The MPT curriculum is along similar lines of the MDS curriculum. The MSc Nursing syllabus has a specific component on practical or hands-on training, wherein the post graduate nursing students are designated specific hours of practical training in appropriate and relevant wards (Indian Nursing Council).

Overall, the analysis of the current undergraduate and postgraduate curricula under disciplines of medicine, dentistry, nursing and physiotherapy indicate that concepts related to IPC in India are slowly beginning to be woven into the health professional curricula. It is encouraging to note that efforts to promote collaborative working across interdisciplinary settings is being reflected at various levels such as inclusion of competency based curriculum, or enabling rotational or interdepartmental exposure across departments of different disciplines. Common topics such as human anatomy, physiology, biochemistry, microbiology, pathology, and pharmacology are being taught across all four different professional curricula. This nevertheless heralds the first step towards promoting shared learning. There remains a huge scope for strengthening this component further so as to enable cross-learning across different disciplines. We additionally observed that there is a need to bring greater focus on addressing coexisting multiple diseases and multimorbidity issues in healthcare, in the curricula of both undergraduate and postgraduate healthcare professionals in India.

It may be noted that the above observations pertain to those obtained from syllabi mapping based on availability in public domain. Discussions regarding multimorbidity or IPC which may get transacted in class are not captured in the syllabus may have been omitted in our observations.

\section{DISCUSSION}

Considering its incidence and socioeconomic impact, multimorbidity constitutes a challenge to healthcare services in the 21 st century (Abebe et al., 2020). Studies in different countries have shown that it is not chronic conditions by themselves that increase the resource cost; rather, it is the number of types of conditions, that is, multimorbidity which is responsible (Kowal et al., 2015). In India, various studies have indicated the prevalence to be ranging from 8 to $33 \%$ in adults with primary care being frequently confronted with these individuals (Pati et al., 2017b; Swain et al., 2017; Kshatri et al., 2020; Pati et al., 2020; Vargese et al., 2020). Multimorbidity with its composition of multiple illnesses poses complex challenges for patients and providers alike in primary care. Ironically, majority of our medical research and education has focused on single diseases till date. Existing models of care for chronically ill patients are mostly configured around the management of each disease separately and the clinical practice guidelines on which such models are based also focus on single diseases. Further, the traditional focus of India's healthcare systems has been inclined towards treating infections and delivery of acute episodic care than chronic continuous care and thus not optimally suited to address the needs of individuals with multimorbidity.

To cater to the above, delivery of holistic and integrated care becomes crucial. This entails healthcare professionals from multiple disciplines to come together and work in a team to provide comprehensive and quality health services within and across settings. It can only happen when these professionals have received adequate training in their education on IPC related aspects. Moreover, this is achieved even better when health professionals not only learn to effectively communicate with each other, but also with patients, their families, and the community in a collaborative and responsible way. A recent systematic review that discusses challenges faced by general physicians (GP) in ensuring quality patient care in case of multimorbidity management, highlighted concerns around poor communication with patients and with healthcare professionals (Damarell et al., 2020). This led to limitations in GP's sharing of care for multimorbidity patients with health professionals from outside primary care, resulting in a sense of "professional isolation" among them.

Against this background, we undertook this study to assess the curricular elements in the context of health communication in general, with a particular focus on IPC for delivery of multidisciplinary care for multimorbidity management in India. We found that there were exclusive courses on health communication being delivered at different levels. However, many of these courses continue to be offered outside the realm of medical education and at curricular level. As such, there is limited integration of these courses into the current curriculum of medication education and training in India. Moreover, the focus on IPC is still in stages of infancy. We did not find any specific institution or organization offering courses designed around IPC or multimorbidity. Moreover, most of the curricula focused on single non-communicable 
disease and did not chart or clearly articulate the management guidelines for multimorbidity. Similar inferences have also been highlighted in an earlier survey wherein majority of students across all disciplines accepted the lack of knowledge, training and confidence in comorbidity care and were unable to identify specific teaching on comorbidities (Lawson et al., 2017). Additionally, the health education institution representatives also had found no specific references to comorbidity in current health education curricula. Therefore, it is essential that the IPC for multimorbidity is built into to current health professional curricula, along with emphasis on the need for appropriate health communication.

At the primary care level, there is an unmet need for delivery of integrated care for multimorbid patients, which is more challenging due to limited availability of primary care providers trained in multimorbidity management. Unlike chronic diseases, there are no widely accepted care models for multimorbidity at present. So far these have been based on general models for integrated care for chronic diseases such as the Chronic Care Model or the Guided Care Model (Struckmann et al., 2018). The constructs for the implementation of the multimorbiditiy aspect in such models have been shown to be absent so far (Boehmer et al., 2018). In view of this existing gap, a comprehensive conceptual SELFIE (Sustainable intEgrated chronic care models for multi-morbidity: delivery, FInancing, and performancE) framework of integrated care in multimorbidity has been recently proposed, which is expected to guide development and delivery of integrated care for multimorbidity (Leijten et al., 2018).

In addition, there are other challenges. Most of the available medical research, guidelines or treatments are designed to address single diseases. Vertical and disease specific healthcare programmes, inclined more towards infectious diseases, are functioning towards rendering acute care services. The multimorbidity component is also excluded from clinical trials, thus making it difficult to generalize the results.

Unless health systems do not invest in integrating IPC into health communication/promotion/education components in the formative phase, there cannot be sustainable gains in population health outcomes (Iroku-Malize et al., 2013; Oeseburg et al., 2013; van der Gulden et al., 2020). Going forward, primary health care in the shape of HWC should steer the journey for patient-centred care by taking along all professionals in this journey. Strong evidence based advocacy at the academic and policy level could catalyse the operationalization.

In 'Multimorbidity: Technical Series on Safer Primary Care', the World Health Organization recognizes that one of the reason that multimorbidity patients are at higher risk of safety issues is the need for clear communication and patient-centred care due to complex patient needs. It stresses on the need for improved communication with patients, increased communication and coordination across different types of care including primary, secondary and also social care, strengthening workforce capacity through inter-professional education, with particular reference to multimorbidity (World Health Organization, 2016). There lies a high level of interdependence among healthcare professionals from multiple services who are responsible for taking care of patients with multimorbidity at the primary care level. These professionals need to be trained in a way such that they are able to cater to the multiple needs and problems of multimorbidity patients (Lawson et al., 2017). In view of this, we suggest the following:

- There is a need to integrate the health communication, health education and health promotion aspects into the current medical education and training system. Healthcare professionals, in their formatting stages should be trained in these aspects to be able to better yield to the needs of IPC.

- Health communication and IPC aspects in the health professional curricula should be further strengthened. This can be initiated with a series of small steps such as teaching on common topics, joint course-work, joint seminars, joint internships. However, in the long run, measures to introduce significant changes in the curriculum must be undertaken. For example, a summer attachment for the undergraduate medical students at the HWCs could be considered as a curricular intervention. Efforts should be directed to a trans-disciplinary learning collaborative team-oriented approach in the health professional curricula.

- The capacity of faculty members with different disciplinary background and inter-professional teaching expertise to supervise students and conduct research should be built upon. Senior leadership and administrators in academic institutions should support such capacity building and must be key partners in this process. At the department and college/school level, faculty members must take the lead in developing the curricular frameworks and time frames needed to provide opportunities for various types of inter-professional interactions for students across all health professions. In parallel, the desire and preparedness among students of various disciplines to work together in order to facilitate teamwork skills should also be assessed and enhanced.

- It is to be impressed upon that each patient with multimorbidity is recognized as an individual with unique multicomponent care aspects, rather than focusing on primary morbidity alone or singular morbidity in silo. Management of multimorbidity in primary care should now be acknowledged as a priority for health policymakers and healthcare providers. Necessary research and curricular interventions required for enabling the delivery of quality and efficient health services to patients with multimorbidity needs to be introduced (The Academy of Medical Sciences, 2018).

- Future studies to have a better understanding of the status of IPC in India, and also their linkages and relevance in the context of multimorbidity needs to be conducted. This could be done through a mixed-method study that involves 1) primary data collection from all medical universities/institutes through specifically designed questionnaires or 2) in-depth interviews with range of stakeholders (faculty, students, curriculum planners, academic administrators, and practitioners) across different disciplines of medicine, dentistry, nursing, allied health services, and physiotherapy. 


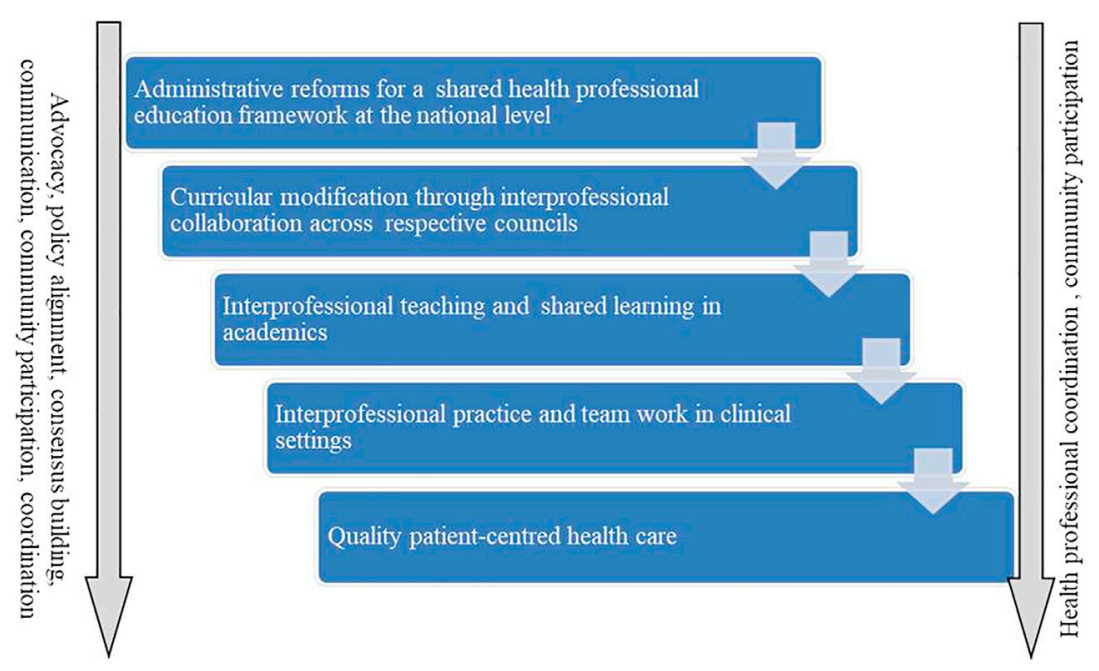

FIGURE 1 | Roadmap to the development of inter-professional care education in India.

Figure 1 provides a roadmap towards inclusion of the concept of IPC and multimorbidity in health professional education in India. Through necessary advocacy and informed decision making, academic consensus for a shared health professional education framework could be explored. This is in congruence with the newly formulated New Education Policy which promulgates cross-disciplinary and inter-disciplinary learning (Ministry of Human Resource Development, Government of India). The policy revision may then be followed by appropriate curricular modifications through fostering necessary collaboration across respective Councils. Once necessary modifications are made, inter-professional teaching and shared learning should be encouraged in academia, and delivery of IPC through team work configured around multimorbidity may be practiced in clinical settings.

\section{FUTURE IMPLICATIONS AND CONCLUSION}

In the present study, we assessed the prevailing undergraduate and postgraduate healthcare professional curricula to understand the focus on health communication and on IPC aimed to deliver multidisciplinary care for managing multimorbidity. These entities pose stronger relevance in the context of delivering collaborative team-based care for patients with multimorbidity, more so in case of primary care settings. Our curricular assessment shows that while there are some ongoing efforts around delivery of health communication education, there is still initial focus on IPC among healthcare trainees, leaving a huge scope remains for strengthening this aspect. Further, the need for curricular focus on recognizing multimorbidity as a health care challenge for patients is still to be emphasized. This would not only prepare the future healthcare professionals to ably manage the intricate care demands of multimorbidity through fostering team work, but create scope for cross dialogue and transdisciplinary learning among students. Since our findings were limited to the secondary analysis of syllabi only, future studies exploring factual learning from classroom sessions through primary study and interviews with students, faculty and academicians should be undertaken to garner a better understanding of the present scenario and provide insights for future curricular roadmap.

\section{DATA AVAILABILITY STATEMENT}

Data supporting the results reported in this article may be made available from the corresponding author upon reasonable request.

\section{AUTHOR CONTRIBUTIONS}

SP conceptualized the study. RS and SP designed the study methodology and developed the data extraction plan. RS prepared the first draft of the article which was then refined and finalized by PM and SP. The article has been read and approved by all the authors.

\section{ACKNOWLEDGMENTS}

We express our deep gratitude and appreciation to all the institutes and organizations for making the relevant syllabi available in public domain. We are thankful to Banambar Sahoo, and Srikanta Kanungo, ICMR RMRC Bhubaneswar, Odisha for their support. We acknowledge the cooperation of RMRC Bhubaneswar administration and finance team. 


\section{REFERENCES}

Abebe, F., Schneider, M., Asrat, B., and Ambaw, F. (2020). Multimorbidity of Chronic Non Communicable Diseases in Low-And Middle-Income Countries: A Scoping Review. J. Comorbidity 10, 1-13. doi:10.1177/2235042x20961919

Arokiasamy, P. (2018). India's Escalating burden of Non-communicable Diseases. Lancet Glob. Health 6, e1262-e1263. doi:10.1016/s2214-109x(18)30448-0

Bigna, J. J., and Noubiap, J. J. (2019). The Rising burden of Non-communicable Diseases in Sub-Saharan Africa. Lancet Glob. Health 7, e1295-e1296. doi:10.1016/s2214-109x(19)30370-5

Boehmer, K. R., Abu Dabrh, A. M., Gionfriddo, M. R., Erwin, P., and Montori, V. M. (2018). Does the Chronic Care Model Meet the Emerging Needs of People Living with Multimorbidity? A Systematic Review and Thematic Synthesis. PLoS One 13, e0190852. doi:10.1371/journal.pone.0190852

Damarell, R. A., Morgan, D. D., and Tieman, J. J. (2020). General Practitioner Strategies for Managing Patients with Multimorbidity: a Systematic Review and Thematic Synthesis of Qualitative Research. BMC Fam. Pract. 21, 1-23. doi:10.1186/s12875-020-01197-8

Dental Council of India Revised BDS Course Regulations, 2007 along with Amendments. Available at: https://www.dciindia.gov.in/Dentistact1948.aspx (Accessed Jan 31, 2021).

Indian Nursing Council Syllabus and Regulations MSc Nursing. Available at: https:// indiannursingcouncil.org/uploads/pdf/159930677710092472745f537c1986880.pdf (Accessed Jan 31, 2021).

Indian Nursing Council Syllabus: Revised Basic BSc Nursing. Available at: https:/www. indiannursingcouncil.org/pdf/BSCSyllabus_2019-20.pdf (Accessed Jan 31, 2021).

Iroku-Malize, T., Matson, C., Freeman, J., McGrew, M., and David, A. (2013). Interprofessional Education. Ann. Fam. Med. 11, 188-189. doi:10.1370/afm.1523

Kassa, M., and Grace, J. (2019). "The Global Burden and Perspectives on Noncommunicable Diseases (NCDs) and the Prevention, Data Availability and Systems Approach of NCDs in Low-Resource Countries," in Public Health in Developing Countries-Challenges and Opportunities. Editors E. E. Anugwom and N. Awofeso (London, United Kingdom: IntechOpen). doi:10.5772/intechopen.89516

Kowal, P., Arokiasamy, P., Afshar, S., Pati, S., and Snodgrass, J. J. (2015). Multimorbidity: Health Care that Counts "past One" for 1.2 Billion Older Adults. The Lancet 385, 2252-2253. doi:10.1016/s0140-6736(15)61062-5

Kshatri, J. S., Palo, S. K., Bhoi, T., Barik, S. R., and Pati, S. (2020). Prevalence and Patterns of Multimorbidity Among Rural Elderly: Findings of the AHSETS Study. Front. Public Health 8, 675. doi:10.3389/fpubh.2020.582663

Lahariya, C. (2018). 'Ayushman Bharat' Program and Universal Health Coverage in India. Indian Pediatr. 55, 495-506. doi:10.1007/s13312-018-1341-1

Lawson, C., Pati, S., Green, J., Messina, G., Strömberg, A., Nante, N., et al. (2017). Development of an International Comorbidity Education Framework. Nurse Educ. Today 55, 82-89. doi:10.1016/j.nedt.2017.05.011

Leijten, F. R. M., Struckmann, V., van Ginneken, E., Czypionka, T., Kraus, M., Reiss, M., et al. (2018). The SELFIE Framework for Integrated Care for MultiMorbidity: Development and Description. Health Policy 122, 12-22. doi:10.1016/j.healthpol.2017.06.002

Ministry of Health and Family Welfare, Government of India (2017). Model Curriculum Handbook Physiotherapy. Available at: https://main.mohfw.gov.in/sites/ default/files/Model\%20Curriculum\%20Handbook_PT_11\%20September\%202017\% 20\%28Final\%29\%20\%281\%29 0.pdf (Accessed Jan 31, 2021).

Ministry of Human Resource Development, Government of India National Education Policy 2020. Available at: https://www.education.gov.in/sites/ upload_files/mhrd/files/NEP_Final_English_0.pdf (Accessed Jan 31, 2021).

National Medical Commission Competency Based Undergraduate Curriculum. Available at: https://www.nmc.org.in/information-desk/for-colleges/ugcurriculum (Accessed Jan 31, 2021).

National Medical Commission PG Curricula. Available at: https://www.nmc.org. in/information-desk/for-colleges/pg-curricula-2 (Accessed Jan 31, 2021).

Oeseburg, B., Hilberts, R., Luten, T. A., van Etten, A. V., Slaets, J. P., and Roodbol, P. F. (2013). Interprofessional Education in Primary Care for the Elderly: a Pilot Study. BMC Med. Educ. 13, 1-7. doi:10.1186/1472-6920-13-161

Pati, S., Mahapatra, P., Dwivedi, R., Athe, R., Sahoo, K. C., Samal, M., et al. (2021a). Multimorbidity and Its Outcomes Among Patients Attending Psychiatric Care Settings: An Observational Study From Odisha, India. Front. Public Health 8, 616480. doi:10.3389/fpubh.2020.616480
Pati, S., Mahapatra, P., Kanungo, S., Uddin, A., and Sahoo, K. C. (2021b). Managing Multimorbidity (Multiple Chronic Diseases) Amid COVID-19 Pandemic: A Community Based Study From Odisha, India. Front. Public Health 8, 584408. doi:10.3389/fpubh.2020.584408

Pati, S., Sharma, K., Zodpey, S., Chauhan, K., and Dobe, M. (2012). Health Promotion Education in India: Present Landscape and Future Vistas. Glob. J. Health Sci. 4, 159-167. doi:10.5539/gjhs.v4n4p159

Pati, S., Sinha, R., and Mahapatra, P. (2019b). Non-communicable Disease Risk Reduction Teaching in India: a Curricular Landscape. Front. Public Health 7 , 133. doi:10.3389/fpubh.2019.00133

Pati, S., Sinha, R., Panda, M., Pati, S., Sharma, A., and Zodpey, S. (2017a). Global Health Teaching in India: a Curricular Landscape. Front. Public Health 5, 259. doi:10.3389/fpubh.2017.00259

Pati, S., Swain, S., Hussain, M. A., van den Akker, M., Metsemakers, J., Knottnerus, J. A., et al. (2015a). Prevalence and Outcomes of Multimorbidity in South Asia: a Systematic Review. BMJ Open 5, e007235. doi:10.1136/bmjopen-2014-007235

Pati, S., Swain, S., Knottnerus, J. A., Metsemakers, J. F. M., and van den Akker, M. (2019a). Health Related Quality of Life in Multimorbidity: a Primary-Care Based Study from Odisha, India. Health Qual. Life Outcomes 17, 116. doi:10.1186/s12955-019-1180-3

Pati, S., Swain, S., Knottnerus, J. A., Metsemakers, J. F. M., and van den Akker, M. (2020). Magnitude and Determinants of Multimorbidity and Health Care Utilization Among Patients Attending Public versus Private Primary Care: a Cross-Sectional Study from Odisha, India. Int. J. Equity Health 19, 57. doi:10.1186/s12939-020-01170-y

Pati, S., Swain, S., Metsemakers, J., Knottnerus, J. A., and van den Akker, M. (2017b). Pattern and Severity of Multimorbidity Among Patients Attending Primary Care Settings in Odisha, India. PLoS One 12, e0183966. doi:10.1371/ journal.pone. 0183966

Pati, S., Swain, S., Hussain, M. A., Kadam, S., and Salisbury, C. (2015b). Prevalence, Correlates, and Outcomes of Multimorbidity Among Patients Attending Primary Care in Odisha, India. Ann. Fam. Med. 13, 446-450. doi:10.1370/afm.1843

Sinha, R., and Pati, S. (2017). Addressing the Escalating burden of Chronic Diseases in India: Need for Strengthening Primary Care. J. Fam. Med Prim Care 6, 701-708. doi:10.4103/jfmpc.jfmpc_1_17

Struckmann, V., Leijten, F. R. M., van Ginneken, E., Kraus, M., Reiss, M., Spranger, A., et al. (2018). Relevant Models and Elements of Integrated Care for MultiMorbidity: Results of a Scoping Review. Health Policy 122, 23-35. doi:10.1016/ j.healthpol.2017.08.008

Swain, S., Pati, S., and Pati, S. (2017). A Chart Review of Morbidity Patterns Among Adult Patients Attending Primary Care Setting in Urban Odisha, India: An International Classification of Primary Care Experience. J. Fam. Med Prim Care 6, 316-322. doi:10.4103/2249-4863.220029

The Academy of Medical Sciences (2018). Multimorbidity: a Priority for Global Health Research. Available at: https://acmedsci.ac.uk/file-download/82222577 (Accessed Jan 31, 2021).

van der Gulden, R., Scherpbier-de Haan, N. D., Greijn, C. M., Looman, N., Tromp, F., and Dielissen, P. W. (2020). Interprofessional Education and Collaboration between General Practitioner Trainees and Practice Nurses in Providing Chronic Care; a Qualitative Study. BMC Med. Educ. 20, 1-9. doi:10.1186/s12909-020-02206-1

Vargese, S. S., Mathew, E., Johny, V., Kurian, N., V, G. A., and Raju, A. S. (2020). Prevalence and Pattern of Multimorbidity Among Adults in a Primary Care Rural Setting. Clin. Epidemiol. Glob. Health 8 (2), 482-485. doi:10.1016/..cegh.2019.10.014

World Health Organization (2016). Multimorbidity: Technical Series on Safer Primary Care. Available at: https://apps.who.int/iris/bitstream/handle/10665/252275/ 9789241511650-eng.pdf;jsessionid=50B75A34C9A6F6DAA61DA95EFF2E9E34? sequence $=1$ (Accessed Jan 31, 2021).

Conflict of Interest: The authors declare that the research was conducted in the absence of any commercial or financial relationships that could be construed as a potential conflict of interest.

Copyright ( 2021 Pati, Sinha and Mahapatra. This is an open-access article distributed under the terms of the Creative Commons Attribution License (CC BY). The use, distribution or reproduction in other forums is permitted, provided the original author(s) and the copyright owner(s) are credited and that the original publication in this journal is cited, in accordance with accepted academic practice. No use, distribution or reproduction is permitted which does not comply with these terms. 